\title{
Prediction and characterization of a novel hemocyanin-derived antimicrobial peptide from shrimp Litopenaeus vannamei
}

\author{
Shen Yang ${ }^{1} \cdot$ He Huang $^{1} \cdot$ Fan Wang $^{1} \cdot$ Jude Juventus Aweya ${ }^{1} \cdot$ Zhihong Zheng $^{1} \cdot$ Yueling Zhang $^{1} \mathbb{C}$
}

Received: 17 January 2018 / Accepted: 23 April 2018 / Published online: 4 May 2018

(c) The Author(s) 2018

\begin{abstract}
Hemocyanin, the multifunctional glycoprotein in the hemolymph of invertebrates, can generate various antimicrobial peptides (AMPs). Given the rising interest in the use of natural therapeutic agents such as AMPs, alternative and more efficient methods for their generation are being explored. In this work, free online software was first applied to predict the generation of antimicrobial peptides from the large subunit of Litopenaeus vannamei hemocyanin. Twenty potential antimicrobial peptides ranging from 1.5 to $1.9 \mathrm{kDa}$ were predicted, five of which had $\alpha$-helical structures and were selected for antibacterial activity testing. The results indicated that these five peptides had antibacterial activity against seven different bacteria. Of the five peptides, one peptide, designated L1, had the strongest antibacterial activity against both Gram-negative and Gram-positive bacteria. Moreover, CD and NMR data showed that L1 had both $\alpha$-helical and $\beta$-turns structural composition, and that these structures were essential for L1's antibacterial activity. Furthermore, SEM analysis revealed that peptide L1 had broadspectrum activity against both Gram-positive and Gram-negative bacteria, as it could destroy the bacterial cell walls and kill the bacteria. Thus, $\mathrm{L} 1$ is a very potent antimicrobial peptide that can be exploited and used in antibacterial therapeutics.
\end{abstract}

Keywords Litopenaeus vannamei $\cdot$ Hemocyanin $\cdot$ Prediction $\cdot$ Antimicrobial peptide

\section{Introduction}

Unlike vertebrates which have both innate and adaptive immune systems, the penaeid shrimp is an invertebrate arthropod with only an innate immune system for protection against pathogens (Bachere et al. 2004). Antimicrobial peptides (AMPs) are a major part of the innate immune defense mechanism and have been extensively studied in the past 20 years. AMPs have broad-spectrum activity against different organisms including Gram-positive and Gram-negative

Handling Editor: E. R. Perez Gonzalez.

Shen Yang and He Huang contributed equally.

Electronic supplementary material The online version of this article (https://doi.org/10.1007/s00726-018-2575-x) contains supplementary material, which is available to authorized users.

Yueling Zhang

zhangyl@stu.edu.cn

1 Department of Biology and Guangdong Provincial Key Laboratory of Marine Biotechnology, School of Science, Shantou University, Shantou 515063, Guangdong, China bacteria (Zhu et al. 2014; Dolashka et al. 2011; Zhuang et al. 2015), as well as fungi, viruses, parasites, and some cancer cells (Choi and Lee 2014; Bulmer et al. 2010; Riciluca et al. 2012; Badani et al. 2014; Liu et al. 2012; Adade et al. 2013; Deng et al. 2016).

Recently, some AMPs derived from high molecular weight proteins have been identified. For instance, Kondori et al. (2011) found that the peptide HLopt2 (20-31) derived from the $\mathrm{N}$-terminal of human lactoferrin had antimicrobial activity against five pathogenic fungi, including Cryptococcus neoformans, Candida albicans, Candida krusei, Candida kefyr and Candida parapsilosis. Nguyen et al. (2010) reported that AMPs could be derived from the C-terminal $\alpha$-helical structure of human chemokines macrophage inflammatory protein-3 $\alpha$ (MIP-3 $\alpha /$ CCL20), interleukin- 8 (IL-8), neutrophil activating protein-2 (NAP-2) and thrombocidin-1 (TC-1), all of which have direct antimicrobial activities. Zhang et al. (2013) have also shown that AJHba peptides from Anguilla japonica had strong antibacterial activities, which was similar to hemoglobin alpha in the liver. A 19-mer peptide, HP (2-20), derived from the N-terminal region of Helicobacter pylori ribosomal protein $\mathrm{L} 1$ (RPL1), was shown to possess broad-spectrum antimicrobial 
activities (Park and Hahm 2005). Similarly, hemocyanin, the most abundant protein in arthropods, is reported to also generate various AMPs (Lee et al. 2003; Destoumieux-Garzon et al. 2001; Wen et al. 2016).

Although there are a number of studies on antimicrobial peptides, there is still limited information on the mechanisms by which these peptides are produced and their mode of action. For these reasons, there is the need to further research and explore the field of antimicrobial peptides and their activity. To be able to leverage on the benefits of AMPs, more efficient methods of generation and/or production are being explored. With the advancement in bioinformatics tools and platforms, several antimicrobial peptides could be accurately and efficiently predicted using laboratory-generated data and the relevant software (Loose et al. 2006; Fjell et al. 2011; Kai et al. 2005). Moreover, since the main features of antimicrobial peptides are known, these bioinformatics tools can be exploited for novel antimicrobial peptides prediction and screening.

Here, we first applied a bioinformatics approach and were able to predict and successfully identified 20 potential AMPs from hemocyanin of Litopenaeus vannamei, 5 of which were further explored. Screening of the peptides showed that peptide $\mathrm{L} 1$ had the strongest antibacterial activity against both Gram-positive and Gram-negative bacteria. Further analysis of the antimicrobial mechanism of L1 using nuclear magnetic resonance and scanning electron microscopy revealed that L1 had an $\alpha$-helical and $\beta$-turns structure, and that these structures were important for its antibacterial activity. Our results indicate that hemocyanin can generate AMPs with strong antimicrobial activity.

\section{Experimental}

\section{Prediction of antibacterial peptides from $L$. vannamei hemocyanin}

Three online softwares, Antibacterial peptides (AntiBP) Server, Collection of Antimicrobial Peptides (CAMP) Server and Antimicrobial Peptide Calculator and Predictor (APD2), were applied to predict antibacterial peptides from L. vannamei hemocyanin large subunit (GenBank: CAB85965.1). Of the softwares used, AntiBP Server (http://www.imtec h.res.in/raghava/antibp/index.html) could predict antibacterial peptides based on protein sequence, with the prediction done by using support vector machine (SVM)-based method via peptide sequences. CAMP (http://www.camp. bicnirrh. res.in) contains information on the conserved sequence signatures, which were captured as patterns and hidden Markov models (HMMs) from 1386 AMPs divided into 45 families. On the other hand, APD2 (http://aps.unmc.edu/AP/predi ction/prediction_main.php) contains 2684 antimicrobial peptides from six kingdoms (266 from bacteria, 4 from archaea, 8 from protists, 13 from fungi, 329 from plants and 2018 from animals).

\section{Predicted peptides and mutant synthesis}

The five predicted peptides (L1, L2, L8, L10 and L12) (Table 2) and three mutants (M1, M2 and M3) (Table 3) were synthesized by a commercial company (Scilight Biotechnology, Beijing, China) using the solid-phase procedure. Briefly, 9-fluorenylmethoxycarbonyl amino acid (Fmocamino acid) and 2,6-dichlorobenzenoylchloride (DCB) were added to the resin to attach the first amino acid. The deprotection was conducted by adding piperidine to remove the protection group, and then the activated amino acid was attached to the peptidyl resin with agitation to couple the next residue. The cycle of deprotection and coupling was repeated until the target peptide was completely synthesized. The peptide was then cleaved from the resin with TFA. The disulfide bridge in the peptide was formed by DMF, and C-terminal amidation was conducted by the amidating enzyme. The synthetic peptides were purified by HPLC with an Agela C18 column. The purity and molecular masses of the purified synthetic peptides were determined using liquid chromatography coupled to mass spectrometry (LC-MS/ ESI).

\section{Minimal inhibitory concentration (MIC)}

Seven bacteria including Vibrio parahaemolyticus, Vibrio fluvialis, Vibrio alginolyticus, Escherichia coli, Aeromonas hydrophila, Staphylococcus aureus and Streptococcus pyogenes were grown in LB medium at $30^{\circ} \mathrm{C}$ and diluted to $10^{6}$ $\mathrm{CFU} / \mathrm{mL}$ in $0.01 \mathrm{M}, \mathrm{pH}$ 7.6 PBS. Peptides were diluted in PBS. The bacteria and diluted peptides were mixed in equal volumes, and then incubated at $30{ }^{\circ} \mathrm{C}$ for $2 \mathrm{~h}$. At the end of the incubation, bacteria were plated on LB agar and incubated at $30{ }^{\circ} \mathrm{C}$ overnight for MIC determination. The lowest concentration of peptide that resulted in the highest level of inhibition was used to define the MIC. Experiments were carried out in triplicate and repeated at least three times. Data are presented as mean \pm standard deviation. GraphPad prism 6 was used to analyze the data with the statistical significance determined by one-way ANOVA and Student's $t$ test, and all experiments were carried out in triplicate.

\section{Circular dichroism (CD) spectrophotometry}

The peptide CD spectra were collected on a Jasco 810 spectropolarimeter (Jasco, Tokyo). The synthesized peptides were dissolved in $25 \mathrm{mM}$ sodium dodecyl sulfate (SDS) to $0.05 \mathrm{mg} / \mathrm{mL}$ with a path length of $1-\mathrm{mm}$ quartz cuvette and data were recorded from 190 to $250 \mathrm{~nm}$. The CD spectra 
were measured at $250 \mathrm{~nm}$, the scanning speed was $100 \mathrm{~nm} /$ min and data points were recorded at $1.0 \mathrm{~nm}$ intervals. The $\mathrm{CD}$ data were processed by the CDpro software.

\section{Prediction of 3D structure}

The 3D structures of synthesized peptides were initially predicted with the online server SWISS-MODEL (http://swiss model.expasy.org/) and edited on PyMol program.

\section{Nuclear magnetic resonance (NMR) analysis}

Synthesized peptides (5 mg) were dissolved in dimethyl sulfoxide (DMSO) plus $150 \mathrm{mM}$ deuterated sodium dodecyl sulfate (SDS) and $0.2 \mathrm{mM}$ 4,4-dimethyl-4-silapentane1 -sulfonic acid (DSS) as an internal reference and adjusted to $\mathrm{pH}$ 5. Samples were loaded into $5 \mathrm{~mm}$ thin-walled glass NMR tubes. All experiments were conducted on a Bruker Avance III $600 \mathrm{MHz}$ NMR spectrometer equipped with a TXI probe and analyzed with MestReNova program. The stability of the alpha helix structure mainly depends on intrachain hydrogen bonds. The $\mathrm{N}-\mathrm{H}$ of each amino acid forms hydrogen bonds with the $\mathrm{C}=\mathrm{O}$ of the fourth amino acids in the front. Analysis of the HMBC spectra was used to find the hydrogen bonding between $\mathrm{N}-\mathrm{H}$ and $\mathrm{C}=\mathrm{O}$.

\section{Scanning electron microscopy (SEM) analysis}

Two bacteria suspensions (V. parahaemolyticus and $S$. aureus) at $10^{6} \mathrm{CFU} / \mathrm{mL}$ were treated with an equal volume of synthesized peptide at lethal doses of $500 \mu \mathrm{g} / \mathrm{mL}$ or $0.01 \mathrm{M} \mathrm{pH} 7.4 \mathrm{PBS}$ for $2 \mathrm{~h}$. Five replicates were pooled together, centrifuged at $2700 \mathrm{~g}$ for $10 \mathrm{~min}$ and washed twice with $0.01 \mathrm{M} \mathrm{pH}$ 7.4 PBS. The samples were then fixed with $4 \%$ formaldehyde for $30 \mathrm{~min}$ before rinsing with deionized water. A series of ethanol solutions $(35,50,75,90,95$ and $100 \%$ ) was used to perform sample dehydration, after which they were mounted on copper tapes and allowed to air dry for 2 days. The samples were finally sputter coated with platinum before imaging under a field emission scanning electron microscope (JEOL JSM-7400F, Japan) (Khara et al. 2015).

\section{Results}

\section{Bioinformatics prediction of AMPs from shrimp hemocyanin}

Hemocyanins are large, copper-containing, multi-subunit oxygen carrier proteins found in the hemolymph of both mollusks and arthropods. The large subunit of $L$. vannamei hemocyanin consists of 671 amino acids and is divided into three domains, including alpha helical region, copper-binding region and Ig-like region (Zhang et al. 2006).

First, two free online software packages (Soft AntiBP Server and CAMP) were used for the antimicrobial peptides prediction. Soft AntiBP Server was used to scan for active polypeptide fragments on the large subunit sequence of $L$. vannamei hemocyanin, while soft CAMP was applied to evaluate the credibility of the predicted active polypeptide fragments. As shown in Table 1, 20 predicted potential AMPs ranging from 1.5 to $1.9 \mathrm{kDa}$ were predicted, among which 2, 10 and 8 came from domain I, domain II and domain III, respectively. Considering that a large number of known AMPs have secondary conformation structures such as $\alpha$-helical (Zeth and Sancho-Vaello 2017; Takahashi et al. 2010) or $\beta$-strand (Yang et al. 2018; Wang et al. 2018), five of the predicted potential AMPs (L1, L2, L8, L10 and L12) had $\alpha$-helical structures predicted by APD2 software and were selected for antibacterial activity testing (Fig. 1).

\section{Antibacterial analysis of five predicted potential AMPs}

To validate whether the five predicted potential AMPs (L1, L2, L8, L10 and L12) had antibacterial activity, they were synthesized (by a commercial company) and their MICs measured with $V$. parahaemolyticus, V. fluvialis, V. alginolyticus, E. coli, A. hydrophila, S. aureus and S. pyogenes. The results indicated that the five predicted potential AMPs had various antibacterial activities against these different bacteria. Notably, L1 had the strongest antibacterial activity against both Gram-negative and Gram-positive bacteria, while L2 had the weakest antimicrobial activity against all seven bacteria. The average MIC of L2 was tenfold that of the average MIC of L1. The AMPs L8, L10 and L12 had some selective antimicrobial activities against these bacteria. For example, L8 and L10 showed moderate antimicrobial activity against $A$. hydrophila, while L10 and L12 showed moderate antimicrobial activity against $V$. alginolyticus (Table 2 and Fig. 2).

\section{Structural analysis of $\mathrm{L1}$}

To elucidate the solution conformation of L1, circular dichroism (CD) experiments were performed. The results indicated that L1 had 34.6\% $\alpha$-helical, $11.2 \% \beta$-strand, 24\% $\beta$-turns and 33.4\% random coil (Fig. 3a and Data Reports S1). Next, the secondary structure of L1 was determined using NMR. HMBC (heteronuclear multiple bond correlation) spectra were used for detailed structural analysis. As shown in Fig. $3 \mathrm{~b}$ and Figure S1, the $\alpha$-helical structure of L1 starts from amino acids $1-5$, and $\mathrm{N}-\mathrm{H}$ of each peptide bond could bind to $\mathrm{C}=\mathrm{O}$ of the fourth peptide bond to form hydrogen bonds, with each peptide bond participating in hydrogen 
Table 1 Prediction of potential antibacterial peptides from large subunit Litopenaeus vannamei hemocyanin

\begin{tabular}{|c|c|c|c|c|c|c|c|}
\hline No. & Peptide sequences & MW (Da) & Start position & Score & $\begin{array}{l}\text { Antibacterial peptide } \\
\text { probability }\end{array}$ & Domain & $\begin{array}{l}\text { Alpha } \\
\text { helical } \\
\text { structure }\end{array}$ \\
\hline L1 & VNFLLHKIYGNIRYS & 1837 & 32 & 0.068 & 0.741 & I & Yes \\
\hline L2 & GGEAVQKLVREVKDG & 1585 & 67 & 0.578 & 0.589 & I & Yes \\
\hline L3 & KPGKFESSFTGTKKN & 1649 & 180 & 0.368 & 0.767 & II & No \\
\hline L4 & DDKYSHHLDRKGGNF & 1788 & 224 & 0.661 & 0.678 & II & No \\
\hline L5 & YSHHLDRKGGNFFWV & 1863 & 227 & 0.216 & 0.641 & II & No \\
\hline L6 & HHLDRKGGNFFWVHH & 1887 & 229 & 0.234 & 0.826 & II & No \\
\hline L7 & HLDRKGGNFFWVHHQ & 1878 & 230 & 1.436 & 0.589 & II & No \\
\hline L8 & GVARIRDLLIIESRI & 1724 & 300 & 0.130 & 0.560 & II & Yes \\
\hline L9 & RIRDLLIIESRIRDA & 1839 & 303 & 0.596 & 0.771 & II & No \\
\hline L10 & RIRDAIAHGYIVDKV & 1726 & 313 & 1.147 & 0.677 & II & Yes \\
\hline L11 & DAIAHGYIVDKVGNH & 1608 & 316 & 0.002 & 0.517 & II & No \\
\hline L12 & YYGALHNTAHIVLGR & 1684 & 357 & 0.013 & 0.627 & II & Yes \\
\hline L13 & GRWNAIELDKFWVKL & 1875 & 515 & 0.398 & 0.511 & III & No \\
\hline L14 & FWVKLPGGTHHIERK & 1799 & 525 & 0.802 & 0.608 & III & No \\
\hline L15 & WVKLPGGTHHIERKC & 1755 & 526 & 0.641 & 0.565 & III & No \\
\hline L16 & NHYGSHGVYPDKRPH & 1751 & 621 & 0.016 & 0.759 & III & No \\
\hline L17 & GSHGVYPDKRPHGYP & 1648 & 624 & 0.648 & 0.624 & III & No \\
\hline L18 & FGHIHLKVFNHGEHI & 1785 & 655 & 0.698 & 0.699 & III & No \\
\hline L19 & GHIHLKVFNHGEHIH & 1775 & 656 & 0.064 & 0.746 & III & No \\
\hline L20 & HIHLKVFNHGEHIHH & 1855 & 657 & 0.353 & 0.637 & III & No \\
\hline
\end{tabular}

Bold type signifies 'Alpha helical structure'

$I$ alpha helical domain, II copper-binding domain, III Ig-like domain

bond formation in the peptide chain. The $\beta$-turn structure starts from amino acids $8-11$, and $\mathrm{C}=\mathrm{O}$ of the first amino acid residue could bind to $\mathrm{N}-\mathrm{H}$ of the fourth amino acid residue to form hydrogen bonds. The secondary structure of L1 is shown in Fig. 3c. Since our NMR data (analyzed with MestReNova software) was consistent with the CD data (processed by the CDpro software), it strongly suggests that the secondary structure composition of L1 peptide is correct.

\section{Analysis of the antibacterial mechanism of AMP L1}

Scanning electron microscopy (SEM) was applied to determine the antibacterial activity against two L1-treated bacteria, V. parahaemolyticus and S. aureus. It was observed that L1 treatment resulted in bacteria roughening and boundary fuzzing with some intracellular inclusions, which indicated that the bacterial cell walls were destroyed, with the degraded polysaccharides aggregating to form a agglomerate structure (Fig. 4).

To further examine the relationship between L1 secondary structure and its antimicrobial activity, different L1 mutants including M1 (Gly to Phe substitution to destroy the $\alpha$-helical structure), M2 (Asp to Gly substitution to mutate the $\beta$-turn structure), and M3 (Asp to Try substitution as control) were designed and synthesized. The results showed that the antibacterial activities of M1 and M2 were decreased 2- to 64-fold (except for S.pyogenes), while no change was observed to that of M3, which indicated that $\alpha$-helical and $\beta$-turn were essential conformations for L1's antibacterial activity (Table 3 ).

\section{Discussion}

Previous studies have shown that hemocyanin exerted its antimicrobial function based on different mechanisms including glycosylation modification (Zhang et al. 2017) and molecular polymorphism (Zhao et al. 2016; Lu et al. 2015; Guo et al. 2013; Zhao et al. 2012, 2013). Here, we predicted and characterized a novel hemocyanin-derived antimicrobial peptide L1 using bioinformatics, followed by experimental validation. The peptide L1 had broad-spectrum activity against both Gram-positive and Gram-negative bacteria. SEM analysis showed that L1 could destroy these bacteria, as their cell walls were seriously damaged with the efflux of intracellular content (Fig. 4), indicating that L1 could kill the bacteria. Peptide L1 is a cationic peptide which has two positively charged residues (Lys7 and Arg13). Although we 


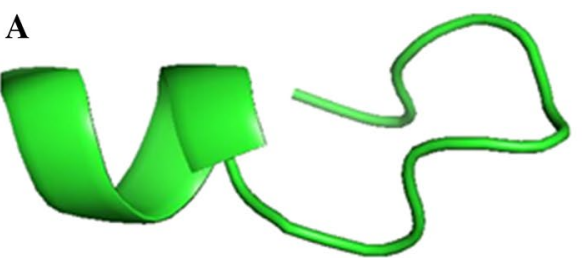

L1(VNFLLHKIYGNIRYS)

C

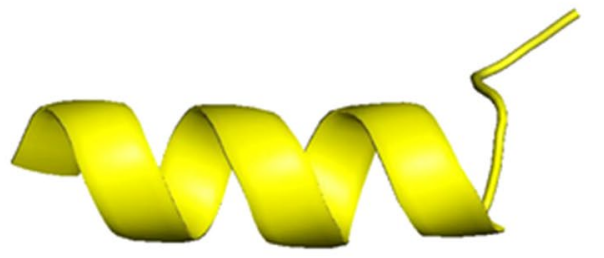

L8(GVARIRDLLIIESRI)

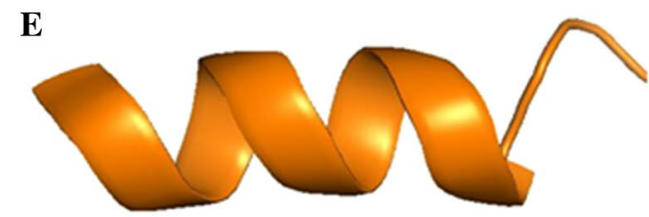

B

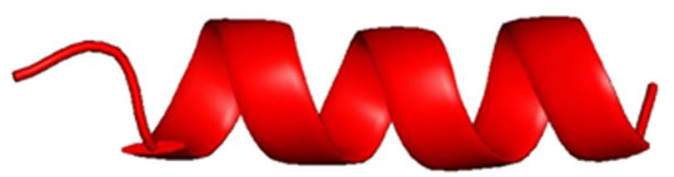

L2(GGEAVQKLVREVKDG)

D

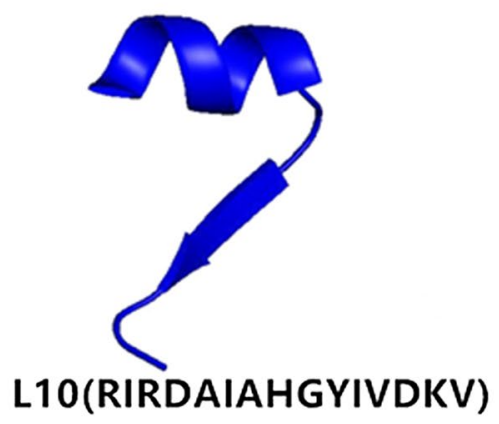

L12(YYGALHNTAHIVLGR)

Fig. 1 Five potential antimicrobial peptides of large subunit L. vannamei hemocyanin L1 (a), L2 (b), L8 (c), L10 (d) and L12 (e) predicted by APD2 software (http://aps.unmc.edu/AP/prediction/prediction_main.php)

Table 2 Antimicrobial activities of the predicted potential AMPs

\begin{tabular}{|c|c|c|c|c|c|c|c|c|}
\hline \multirow[t]{3}{*}{ Peptides } & \multicolumn{7}{|c|}{$\mathrm{MIC}^{\mathrm{a}}\left(\mu \mathrm{gmL}^{-1}\right)$} & \multirow[t]{3}{*}{$\mathrm{GB}^{\mathrm{b}}\left(\mu \mathrm{gmL}^{-1}\right)$} \\
\hline & \multicolumn{5}{|l|}{ Gram negative } & \multicolumn{2}{|c|}{ Gram positive } & \\
\hline & $\begin{array}{l}\text { V. para- } \\
\text { haemolyticus }\end{array}$ & V. fluvialis & V. alginolyticus & E. coli & A. hydrophila & S. aureus & S. pyogenes & \\
\hline L1 & 31.2 & 62.5 & 3.9 & 3.9 & 3.9 & 62.5 & 62.5 & 14.2 \\
\hline L2 & 250 & 125 & 125 & $>250$ & 250 & $>250$ & 250 & 205.1 \\
\hline L8 & 250 & 250 & 250 & $>250$ & 31.3 & 250 & 250 & 185.8 \\
\hline L10 & 250 & 125 & 31.3 & $>250$ & 31.3 & $>250$ & 125 & 113.3 \\
\hline L12 & 250 & 250 & 15.6 & 125 & 125 & $>250$ & 125 & 125.0 \\
\hline Kanamycin & 1 & 1 & 0.5 & 2 & 1 & 2 & 1 & 1.1 \\
\hline
\end{tabular}

did not perform any mutation on Lys7 and Arg13, some studies have reported that these positively charged amino acid residues (Lys and Arg) play an important role in the sequence of antimicrobial peptides (Ahn et al. 2006). In addition, the CD and NMR data showed that peptide L1 had a typical $\alpha$-helix, which was similar to melittin, an antimicrobial peptide consisting of 26 amino acids (Renzo et al. 1988). Thus, the antimicrobial mechanism of L1 may involve electrostatic adsorption onto the cell membrane and form helical hydrophobic environment on the cell membrane. However, a clear-cut mechanism on this needs to be explored in further studies.

Currently, AMPs can be divided into three subgroups based on their secondary structure (Zasloff 2002; Epand and Vogel 1999): (1) $\alpha$-helical antimicrobial peptides (Durr et al. 2006; Pandey et al. 2010), including $\alpha$-defensins, cecropins, 

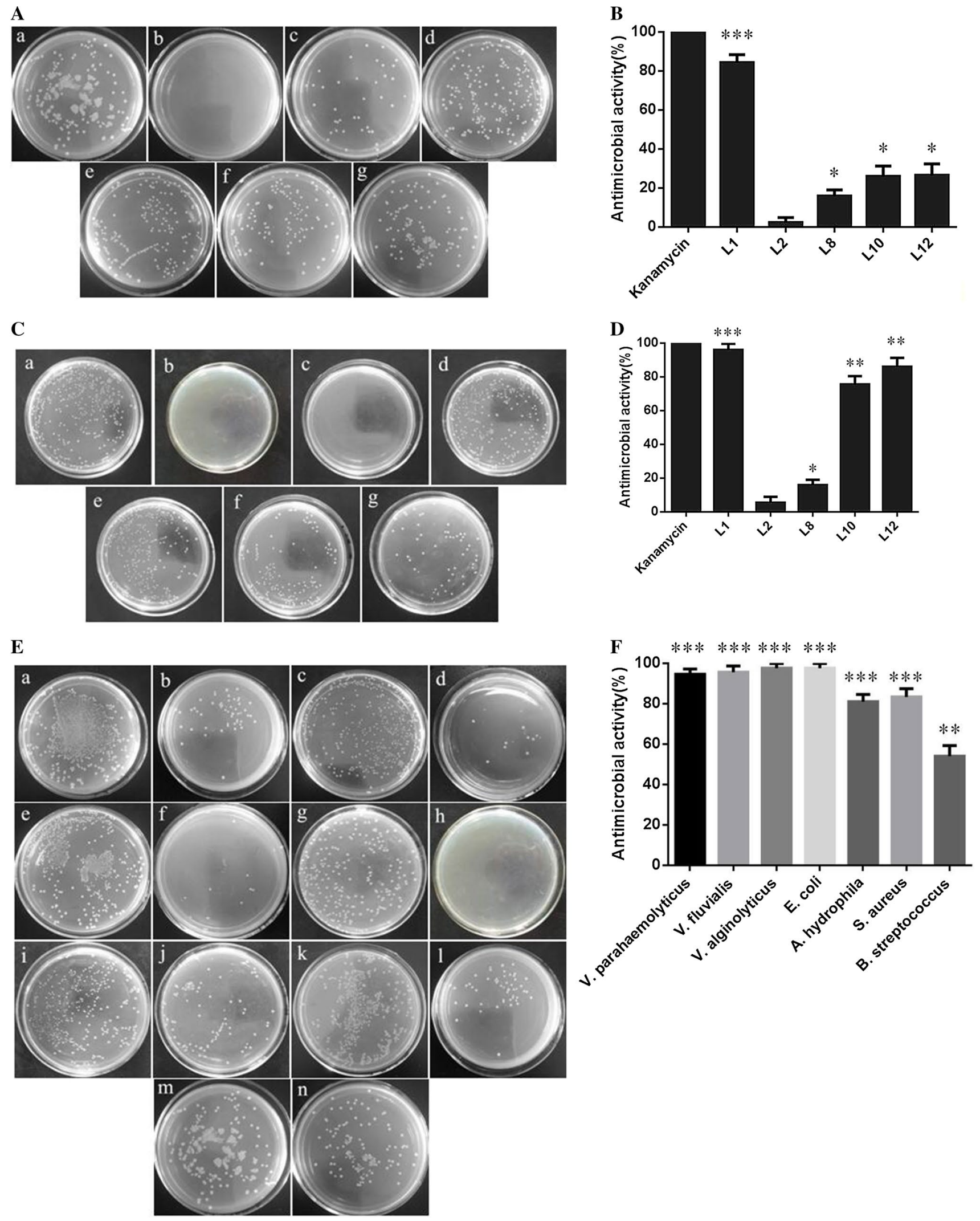
४Fig. 2 The antibacterial activity of five predicted potential AMPs. a, c Bacterial colonies in a Petri dish of 0.01 M pH7.4 PBS (a, negative control), kanamycin (b, positive control), peptide L1 (c), peptide L2 (d), peptide L8 (e), peptide L10 (f) and peptide L12 (g) with V. alginolyticus and $S$. pyogenes, respectively. $\mathbf{b}, \mathbf{d}$ Antimicrobial activity of samples in a and $\mathbf{c}$, respectively. e Bacterial colonies in a Petri dish of $0.01 \mathrm{M} \mathrm{pH}$ 7.4 PBS (a, c, e, g, i, k and m) or peptide L1 (b, d, f, h, j, 1 and $\mathrm{n}$ ) with $V$. parahaemolyticus $(\mathrm{a}, \mathrm{b}), \mathrm{V}$. fluvialis $(\mathrm{c}, \mathrm{d}), \mathrm{V}$. alginolyticus (e, f), E. coli (g, h), A. hydrophila (i, j), S. aureus (k, l) and S. pyogenes $(\mathrm{m}, \mathrm{n})$, respectively. $\mathbf{f}$ Antimicrobial activity of samples in e. The concentration of the five peptides and kanamycin is $0.5 \mathrm{mg} /$ $\mathrm{ml}$. The experiments were carried out in triplicate, repeated at least three times and the significant difference was determined by oneway ANOVA relative to control and indicated by asterisks ${ }^{*} p<0.05$, $* * p<0.01$ and $* * * p<0.001)$. Data are presented as mean \pm SD. Error bars represent standard deviation (SD) for the three independent experiments

magainins, melittin and piscidins; (2) $\beta$-sheets antibacterial peptides, including cyclic $\beta$-sheets, two or more disulfide bonds consisting of $\beta$-sheets (Salgado et al. 2001; Brogden $2005)$, such as gramicidins, $\beta$-defensins, tachyplesins, protegrins, thionin and polymyxin; (3) random coil antibacterial peptides, such as tritrpticin in the family of cathelicidin (Andrushchenko et al. 2007). Given that replacement of Phe with Gly in L1 could effectively destroy its $\alpha$-helical structure as well as its antibacterial activity (Table 3 ), it thus implied the $\alpha$-helical structure was the functional domain of peptide L1, which is synonymous with previous studies (Deslouches et al. 2005). Similarly, when the Gly 10 was replaced with Asp, the $\beta$-turn structure of peptide L1 was destroyed, which also caused a sharp decrease in the antimicrobial activity of L1 (Table 3), therefore suggesting that the $\beta$-turn of L1 could also be the functional domain of this antibacterial peptide. A similar observation was also previously reported by Park et al. (2011). Thus, based on the mutational analysis of $\mathrm{L} 1$, it could be classified as an $\alpha$-helical $\beta$-turn antimicrobial peptide (Yang et al. 2002).

While the peptide L1 had the strongest broad-spectrum antimicrobial activity, a few of the other peptides identified in the screen also had antibacterial activities against some of the tested bacteria. For instance, among the five peptides, which had $\alpha$-helical structures (Fig. 1), L8 had antibacterial activity on A. hydrophila, L10 on V. alginolyticus and $A$. hydrophila, while L12 had antimicrobial activity on $V$. alginolyticus. One other noteworthy finding in this study was that there was some level of correlation between the predicted antimicrobial activity and the experimentally measured minimal inhibitory concentration (MIC) of the peptides. Peptide L1 had the lowest MIC and the highest antimicrobial peptide probability (0.741), while L12 and L10 had medium MIC and antimicrobial peptide probability of 0.627 and 0.677 , respectively. On the other hand, L8 and L2 had a high MIC and the lowest antimicrobial peptide probability of 0.560 and 0.589 , respectively. It is therefore plausible to infer that the capability of bioinformatic tools to provide semi-quantitative prediction on MIC is high, and therefore could shorten or speed up the discovery of AMPs or small molecules. Moreover, this approach in rational design of antimicrobial peptides is much more efficient than the traditional approach, and hence can be optimized for large-scale use. For the peptides identified in this study, further experiments would have to be carried out so as to give a better insight into their mode of action. Until now, most of the hemocyanin-derived peptides have been derived from other species. The AMPs from these other species are generated from hemocyanin at sites distant from the copper-binding domain, because their metal binding sites are mostly hydrophilic. Apart from this, most of the known AMPs are usually found within the C-terminal domain (III) of hemocyanin subunits (Lee et al. 2003; Destoumieux-Garzon et al. 2001; Qiu et al. 2014; Coates and Nairn 2014), because there is an Iglike conserved domain of 252 amino acid residues in the C-terminus of arthropods hemocyanins, which is structurally homologous with human Ig (Zhang et al. 2006, 2017). In the present study, peptide L1 was found to be located in the $\mathrm{N}$-terminal domain (I) (Fig. 3c), which means that the N-terminal domain (I) of large subunit L. vannamei hemocyanin could be a new immune region.

\section{Conclusion}

In conclusion, five potential hemocyanin-derived AMPs were predicted using bioinformatics, followed by antibacterial analysis. Of these, peptide L1 had the strongest antibacterial activity and could be classified as $\alpha$-helical $\beta$-turn 

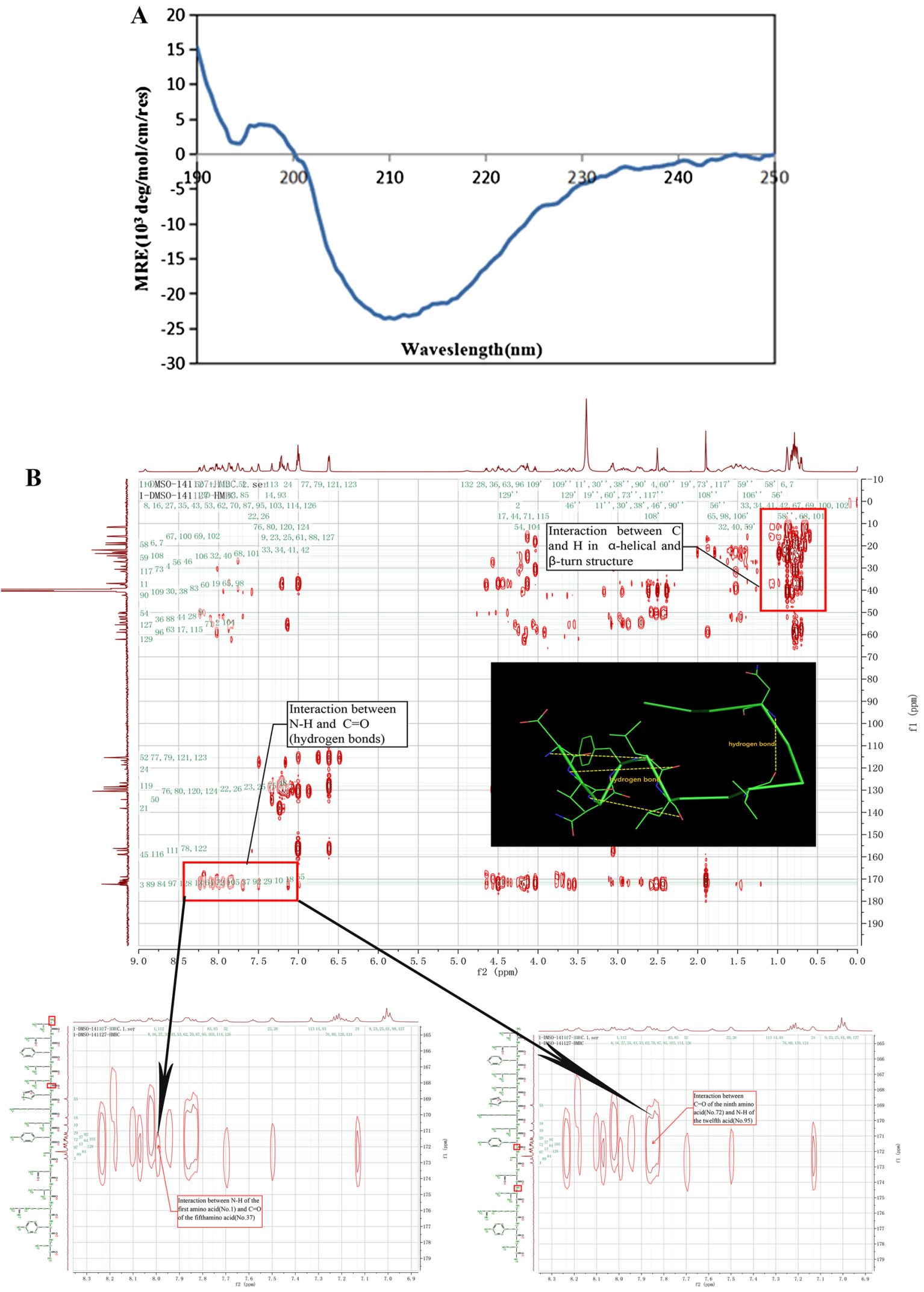

Fig. 3 Structural analysis of peptide L1. a CD spectra of peptide L1 at $25{ }^{\circ} \mathrm{C}$. b HMBC spectrum of peptide L1 in DMSO. c In silico model of peptide L1. (a) Structural views of large subunit L. van- namei hemocyanin hexamer and modeled peptide L1; green part represents L1 in the picture (b) (color figure online) 
C

(a)

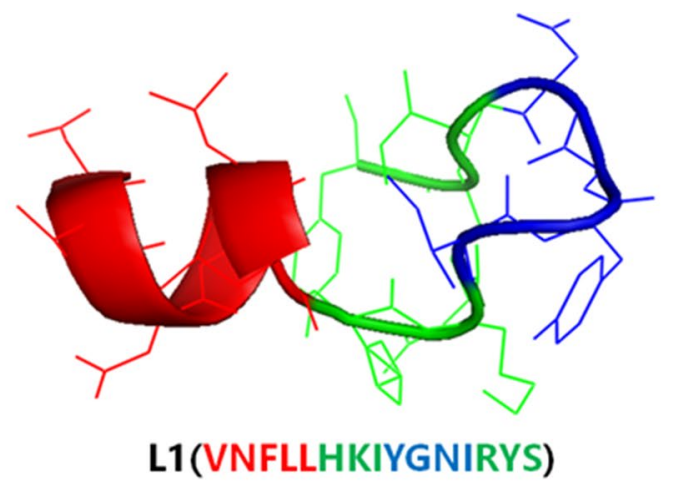

(b)

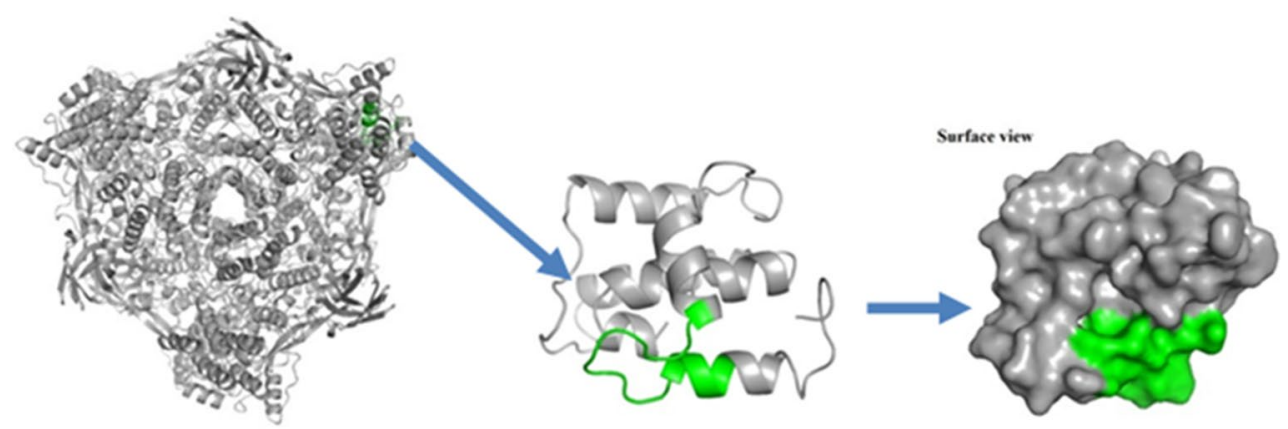

Fig. 3 (continued)

Fig. 4 Scanning electron micrographs of $V$. parahaemolyticus $(\mathbf{a}, \mathbf{b})$ or $S$. aureus $(\mathbf{c}, \mathbf{d})$ with $0.01 \mathrm{M}, \mathrm{pH} 7.4$, PBS $(\mathbf{a}, \mathbf{c})$ and $500 \mu \mathrm{g} / \mathrm{mL}$ peptide $\mathrm{L} 1(\mathbf{b}, \mathbf{d})$, respectively

\section{V. parahaemolvticus}
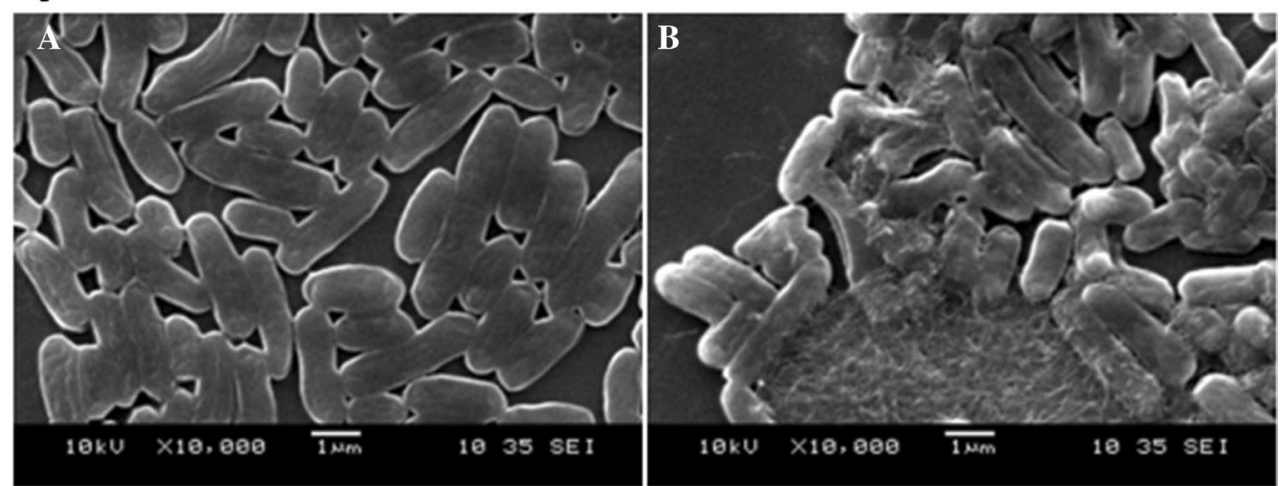

S. aureus
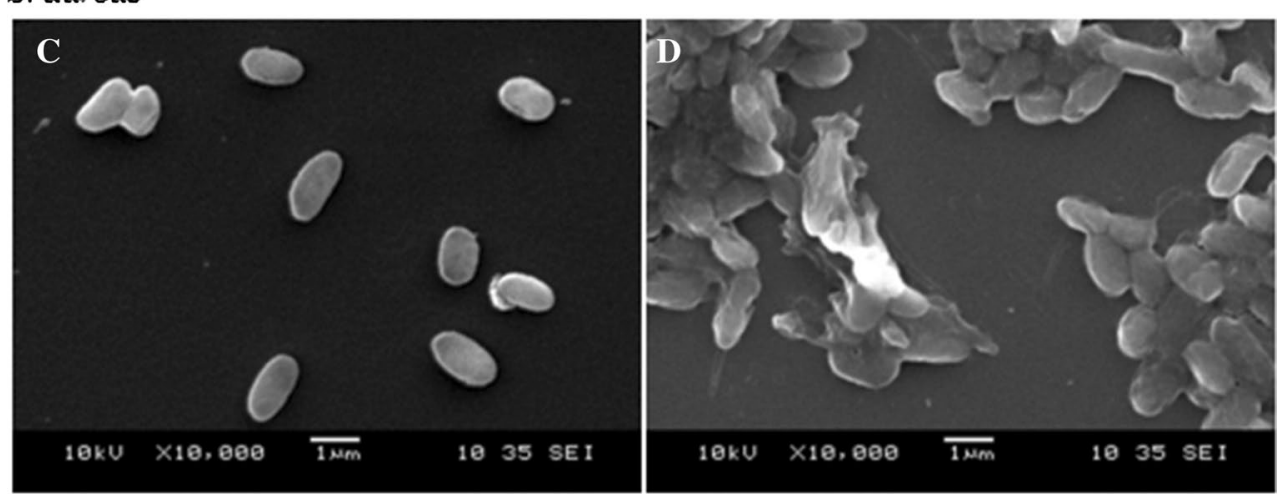
Table 3 Antimicrobial activities of peptide L1 and L1 mutant peptides

\begin{tabular}{|c|c|c|c|c|c|c|c|c|}
\hline \multirow[t]{3}{*}{ Peptides } & \multicolumn{7}{|c|}{$\mathrm{MIC}^{\mathrm{a}}\left(\mu \mathrm{gmL}^{-1}\right)$} & \multirow[t]{3}{*}{$\mathrm{GB}^{\mathrm{b}}\left(\mu \mathrm{gmL}^{-1}\right)$} \\
\hline & \multicolumn{4}{|c|}{ Gram negative } & \multicolumn{3}{|l|}{ Gram positive } & \\
\hline & $\begin{array}{l}\text { V. para- } \\
\text { haemolyti- } \\
\text { cus }\end{array}$ & V. fluvialis & V. alginolyticus & E. coli & A. hydrophila & S. aureus & S. pyogenes & \\
\hline VNFLLHKIYGNIRYS (L1) & 31.2 & 62.5 & 3.9 & 3.9 & 3.9 & 62.5 & 62.5 & 14.2 \\
\hline VNGLLHKIYGNIRYS (M1) & 62.5 & 250 & 250 & 15.6 & 15.6 & $>250$ & 15.6 & 84.3 \\
\hline VNFLLHKIYDNIRYS (M2) & 62.5 & $>250$ & $>250$ & 7.8 & 15.6 & $>250$ & 62.5 & 69.0 \\
\hline VNFLLHKIYGNIRDS (M3) & 31.2 & 62.5 & 3.9 & 3.9 & 3.9 & 62.5 & 62.5 & 14.2 \\
\hline
\end{tabular}

Bold type signifies mutation site

antimicrobial peptide, which is capable of destroying the bacterial membrane by forming an agglomerate structure. This work could provide a more efficient approach to explore some novel AMPs and useful information for the investigation of the shrimp immune defense mechanisms.

Acknowledgements This work was sponsored by the National Natural Science Foundation of China (nos. 31372558 and 31672689) and Natural Science Foundation of Guangdong Province (no. 2017A030311032).

Author contribution statement YLZ conceived and coordinated to the study. SY and HH designed, performed and analyzed the experimental data. ZHZ contributed reagents/materials and provided technical assistance. YLZ, FW and JJA wrote the paper. All authors reviewed the results and approved the final version of the manuscript.

\section{Compliance with ethical standards}

Conflict of interest The authors declare that they have no conflict of interest.

Informed consent Not applicable.

Open Access This article is distributed under the terms of the Creative Commons Attribution 4.0 International License (http://creativeco mmons.org/licenses/by/4.0/), which permits unrestricted use, distribution, and reproduction in any medium, provided you give appropriate credit to the original author(s) and the source, provide a link to the Creative Commons license, and indicate if changes were made.

\section{References}

Adade CM, Oliveira IR, Pais JA, Souto-Padron T (2013) Melittin peptide kills Trypanosoma cruzi parasites by inducing different cell death pathways. Toxicon 69(7):227-239

Ahn HS, Cho W, Kang SH, Ko SS, Park MS, Cho H, Lee KH (2006) Design and synthesis of novel antimicrobial peptides on the basis of a helical domain of Tenecin 1, an insect defensin protein, and structure-activity relationship study. Peptides 27:640-648

Andrushchenko VV, Vogel HJ, Prenner EJ (2007) Interactions of tryptophan-rich cathelicidin antimicrobial peptides with model membranes studied by differential scanning calorimetry. Biochim Biophys Acta 1768(10):2447-2458

Bachere E, Gueguen Y, Gonzalez M, de Lorgeril J, Garnier J, Romestand B (2004) Insights into the anti-microbial defense of marine invertebrates: the penaeid shrimps and the oyster Crassostrea gigas. Immunol Rev 198:149-168

Badani H, Wimley WC, Garry RF (2014) Peptide entry inhibitors of enveloped viruses: the importance of interfacial hydrophobicity. Biochim Biophys Acta 1838 9:2180-2197

Brogden KA (2005) Antimicrobial peptides: pore formers or metabolic inhibitors in bacteria? Nat Rev Microbiol 3(3):238-250

Bulmer MS, Lay F, Hamilton C (2010) Adaptive evolution in subterranean termite antifungal peptides. Insect Mol Biol 19(5):669-674

Choi H, Lee DG (2014) Antifungal activity and pore-forming mechanism of astacidin 1 against Candida albicans. Biochimie 105(10):58-63

Coates CJ, Nairn J (2014) Diverse immune functions of hemocyanins. Dev Comp Immunol 45(1):43-55

Deng X, Qiu Q, Wang X, Huang W, Qian H (2016) Design, synthesis, and biological evaluation of novel cholesteryl peptides with anticancer and multidrug resistance-reversing activities. Chem Biol Drug Des 87(3):374-381

Deslouches B, Phadke SM, Lazarevic V, Cascio M, Islam K, Montelaro RC, Mietzner TA (2005) De novo generation of cationic antimicrobial peptides: influence of length and tryptophan substitution on antimicrobial activity. Antimicrob Agents Chemother 49(1):316-322

Destoumieux-Garzon D, Saulnier D, Garnier J, Jouffrey C, Bulet P, Bachere E (2001) Crustacean immunity. Antifungal peptides are generated from the $\mathrm{C}$ terminus of shrimp hemocyanin in response to microbial challenge. J Biol Chem 276(50):47070-47077

Dolashka P, Moshtanska V, Borisova V, Dolashki A, Stevanovic S, Dimanov T, Voelter W (2011) Antimicrobial proline-rich peptides from the hemolymph of marine snail Rapana venosa. Peptides 32(7):1477-1483

Durr UHN, Sudheendra US, Ramamoorthy A (2006) LL-37, the only human member of the cathelicidin family of antimicrobial peptides. Biochim Et Biophys Acta Biomembr 1758(9):1408-1425

Epand RM, Vogel HJ (1999) Diversity of antimicrobial peptides and their mechanisms of action. Biochim Biophys Acta 1462(1-2):11-28

Fjell CD, Hiss JA, Hancock RE, Schneider G (2011) Designing antimicrobial peptides: form follows function. Nat Rev Drug Discov 11(1):37-51

Guo L, Zhao X, Zhang Y, Wang Z, Zhong M, Li S, Lun J (2013) Evidences of SNPs in the variable region of hemocyanin Iglike domain in shrimp Litopenaeus vannamei. Fish Shellfish Immunol 35(5):1532-1538 
Kai H, Volkmerengert R, Walter T, Hancock REW (2005) Highthroughput generation of small antibacterial peptides with improved activity. Nat Biotechnol 23(8):1008-1012

Khara JS, Lim FK, Wang Y, Ke XY, Voo ZX, Yang YY, Lakshminarayanan R, Ee PLR (2015) Designing alpha-helical peptides with enhanced synergism and selectivity against Mycobacterium smegmatis: discerning the role of hydrophobicity and helicity. Acta Biomater 28:99-108

Kondori N, Baltzer L, Dolphin GT, Mattsby-Baltzer I (2011) Fungicidal activity of human lactoferrin-derived peptides based on the antimicrobial alpha beta region. Int J Antimicrob AG 37(1):51-57

Lee SY, Lee BL, Soderhall K (2003) Processing of an antibacterial peptide from hemocyanin of the freshwater crayfish Pacifastacus leniusculus. J Biol Chem 278(10):7927-7933

Liu K, Feng X, Ma Z, Luo C, Zhou B, Cao R, Huang L, Miao D, Pang R, He D, Lian X, Chen P (2012) Antiviral activity of phage display selected peptides against Porcine reproductive and respiratory syndrome virus in vitro. Virology 432(1):73-80

Loose C, Jensen K, Rigoutsos I, Stephanopoulos G (2006) A linguistic model for the rational design of antimicrobial peptides. Nature 443(7113):867-869

Lu X, Lu H, Guo LL, Zhang ZH, Zhao XL, Zhong MQ, Li SK, Zhang YL (2015) Cloning and characterization of a novel hemocyanin variant LvHMCV4 from shrimp Litopenaeus vannamei. Fish Shellfish Immunol 46(2):398-405

Nguyen LT, Chan DI, Boszhard L, Zaat SA, Vogel HJ (2010) Structurefunction studies of chemokine-derived carboxy-terminal antimicrobial peptides. Biochim Biophys Acta 1798(6):1062-1072

Pandey BK, Ahmad A, Asthana N, Azmi S, Srivastava RM, Srivastava S, Verma R, Vishwakarma AL, Ghosh JK (2010) Cell-selective lysis by novel analogues of melittin against human red blood cells and Escherichia coli. Biochemistry 49(36):7920-7929

Park Y, Hahm KS (2005) Effects of N- and C-terminal truncation of HP (2-20) from Helicobacter pylori ribosomal protein L1 (RPL1) on its anti-microbial activity. Biotechnol Lett 27(3):193-199

Park C, Cho J, Lee J, Lee DG (2011) Membranolytic antifungal activity of arenicin-1 requires the $\mathrm{N}$-terminal tryptophan and the beta-turn arginine. Biotechnol Lett 33(1):185-189

Qiu C, Sun J, Liu M, Wang B, Jiang K, Sun S, Meng X, Luo Z, Wang L (2014) Molecular cloning of hemocyanin cDNA from Fenneropenaeus chinensis and antimicrobial analysis of two C-terminal fragments. Mar Biotechnol (NY) 16(1):46-53

Renzo B, Tappin MJ, Annalisa P, Harvey TS, Carver JA, Campbell ID (1988) The structure of melittin. Eur J Biochem 173(1):139-146

Riciluca KC, Sayegh RS, Melo RL, Silva PI Jr (2012) Rondonin an antifungal peptide from spider (Acanthoscurria rondoniae) haemolymph. Results Immunol 2:66-71

Salgado J, Grage SL, Kondejewski LH, Hodges RS, McElhaney RN, Ulrich AS (2001) Membrane-bound structure and alignment of the antimicrobial beta-sheet peptide gramicidin $\mathrm{S}$ derived from angular and distance constraints by solid state 19F-NMR. J Biomol NMR 21(3):191-208

Takahashi D, Shukla SK, Prakash O, Zhang G (2010) Structural determinants of host defense peptides for antimicrobial activity and target cell selectivity. Biochimie 92(9):1236-1241
Wang YT, Zeng ZY, Zhang XH, Shi Q, Wang CG, Hua ZL, Li H (2018) Identification and characterization of a novel defensin from Asian green mussel Perna viridis. Fish Shellfish Immunol 74:242-249

Wen Y, Zhan SX, He H, Zhong MQ, Chen JH, You CH, Fan W, Zhang YL (2016) Identification and characterization of an $18.4 \mathrm{kDa}$ antimicrobial truncation from shrimp Litopenaeus vannamei hemocyanin upon Vibrio parahaemolyticus infection. Fish Shellfish Immunol 56:450-458

Yang ST, Yub Shin SY, Kim YC, Kim Y, Hahm KS, Kim JI (2002) Conformation-dependent antibiotic activity of tritrpticin, a cathelicidin-derived antimicrobial peptide. Biochem Biophys Res Commun 296(5):1044-1050

Yang R, Zhang GJ, Zhang FR, Li ZJ, Chun Huang C (2018) Membrane permeabilization design of antimicrobial peptides based on chikungunya virus fusion domain scaffold and its antibacterial activity against gram-positive Streptococcus pneumoniae in respiratory infection. Biochimie 146:139-147

Zasloff M (2002) Antimicrobial peptides of multicellular organisms. Nature 415(6870):389-395

Zeth K, Sancho-Vaello E (2017) The human antimicrobial peptides dermcidin and LL-37 show novel distinct pathways in membrane interactions. Front Chem 5:86

Zhang YL, Wang SY, Xu AL, Chen J, Lin BK, Peng XX (2006) Affinity proteomic approach for identification of an IgA-like protein in Litopenaeus vannamei and study on its agglutination characterization. J Proteome Res 5(4):815-821

Zhang DL, Guan RZ, Huang WS, Xiong J (2013) Isolation and characterization of a novel antibacterial peptide derived from hemoglobin alpha in the liver of Japanese eel, Anguilla japonica. Fish Shellfish Immunol 35(3):625-631

Zhang YL, Peng B, Li H, Yan F, Wu HK, Zhao XL, Lin XM, Min SY, Gao YY, Wang SY (2017) C-terminal domain of hemocyanin, a major antimicrobial protein from Litopenaeus vannamei: structural homology with immunoglobulins and molecular diversity. Front Immunol 8:611

Zhao XL, Guo LL, Zhang YL, Liu Y, Zhang XY, Lun JS, Chen JH, Li YY (2012) SNPs of hemocyanin C-terminal fragment in shrimp Litopenaeus vannamei. FEBS Lett 586(4):403-410

Zhao S, Lu X, Zhang YL, Zhao XL, Zhong MQ, Li SK, Lun JS (2013) Identification of a novel alternative splicing variant of hemocyanin from shrimp Litopenaeus vannamei. Immunol Lett 154(1-2):1-6

Zhao XL, Guo LL, Lu X, Lu H, Wang F, Zhong MQ, Chen JH, Zhang YL (2016) Evidences of abundant hemocyanin variants in shrimp Litopenaeus vannamei. Mol Immunol 77:103-112

Zhu X, Dong N, Wang ZY, Ma Z, Zhang LC, Ma QQ, Shan AS (2014) Design of imperfectly amphipathic alpha-helical antimicrobial peptides with enhanced cell selectivity. Acta Biomater 10(1):244-257

Zhuang J, Coates CJ, Zhu H, Zhu P, Wu Z, Xie L (2015) Identification of candidate antimicrobial peptides derived from abalone hemocyanin. Dev Comp Immunol 49(1):96-102 